\title{
Universiteit
}

Leiden

The Netherlands

\section{Maternal antenatal depression and child mental health: moderation by genomic risk for attention-deficit/hyperactivity disorder}

Chen, L.M.; Tollenaar, M.S.; Dass, S.H.A.; Bouvette-Turcot, A.A.; Pokhvisneva, I.;

Gaudreau, H.; ... ; O'Donnell, K.J.

\section{Citation}

Chen, L. M., Tollenaar, M. S., Dass, S. H. A., Bouvette-Turcot, A. A., Pokhvisneva, I., Gaudreau, H., ... O'Donnell, K. J. (2021). Maternal antenatal depression and child mental health: moderation by genomic risk for attention-deficit/hyperactivity disorder. Dev Psychopathol, 32(5), 1810-1821. doi:10.1017/S0954579420001418

Version: Publisher's Version

License: $\quad$ Licensed under Article 25fa Copyright Act/Law (Amendment Taverne)

Downloaded from: https://hdl.handle.net/1887/3250326

Note: To cite this publication please use the final published version (if applicable). 


\title{
Special Issue Article
}

\section{Maternal antenatal depression and child mental health: Moderation by genomic risk for attention-deficit/hyperactivity disorder}

\author{
Lawrence M. Chen ${ }^{1,2}$ (D), Marieke S. Tollenaar ${ }^{3,4}$ (D), Shantala A. Hari Dass ${ }^{1,2}$, Andrée-Anne Bouvette-Turcot ${ }^{1,2}$, \\ Irina Pokhvisneva ${ }^{1,2}$, Hélène Gaudreau ${ }^{1,2}$, Carine Parent ${ }^{1,2}$, Josie Diorio ${ }^{1,2,5}$, Lisa M. McEwen ${ }^{6}$, Julia L. Maclsaac ${ }^{6}$, \\ Michael S. Kobor ${ }^{6,7}$, Roseriet Beijers ${ }^{8,9}$, Carolina de Weerth ${ }^{9}$ (D), Patricia P. Silveira ${ }^{1,2}$ (D), Sherif Karama ${ }^{1,2}$, \\ Michael J. Meaney $1,2,5,7,10$, Kieran J. O’Donnell $1,2,7,11$ (D) and The MAVAN Study Team \\ ${ }^{1}$ Douglas Research Centre, Department of Psychiatry, McGill University, Montreal, QC, Canada; ${ }^{2}$ Ludmer Centre for Neuroinformatics \& Mental Health, McGill \\ University, Montreal, QC, Canada; ${ }^{3}$ Clinical Psychology Unit, Institute of Psychology, Leiden University, Leiden, the Netherlands; ${ }^{4}$ Leiden Institute for Brain and \\ Cognition, Leiden University, Leiden, the Netherlands; ${ }^{5}$ Sackler Program for Epigenetics \& Psychobiology, McGill University, Montreal, QC, Canada; ${ }^{6}$ Centre for \\ Molecular Medicine and Therapeutics, University of British Columbia, Vancouver, BC, Canada; ${ }^{7}$ Child and Brain Development Program, CIFAR, Toronto, ON, Canada; \\ ${ }^{8}$ Behavioural Science Institute, Radboud University, Nijmegen, the Netherlands; ${ }^{9}$ Department of Cognitive Neuroscience, Donders Institute for Brain, Cognition \& \\ Behaviour, Radboud University Medical Center, Nijmegen, the Netherlands; ${ }^{10}$ Singapore Institute for Clinical Sciences, Agency for Science, Technology \& Research \\ (A ${ }^{\star}$ STAR), Singapore and ${ }^{11}$ Yale Child Study Center \& Department of Obstetrics, Gynecology \& Reproductive Sciences, Yale School of Medicine, New Haven, CT, USA
}

\begin{abstract}
Maternal antenatal depression strongly influences child mental health but with considerable inter-individual variation that is, in part, linked to genotype. The challenge is to effectively capture the genotypic influence. We outline a novel approach to describe genomic susceptibility to maternal antenatal depression focusing on child emotional/behavioral difficulties. Two cohorts provided measures of maternal depression, child genetic variation, and child mental health symptoms. We constructed a conventional polygenic risk score (PRS) for attentiondeficit/hyperactivity disorder $(\mathrm{ADHD})\left(\mathrm{PRS}_{\mathrm{ADHD}}\right)$ that significantly moderated the association between maternal antenatal depression and internalizing problems at 60 months $\left(p=2.94 \times 10^{-4}, R^{2}=.18\right)$. We then constructed an interaction PRS (xPRS) based on a subset of those single nucleotide polymorphisms from the $\mathrm{PRS}_{\mathrm{ADHD}}$ that most accounted for the moderation of the association between maternal antenatal depression and child outcome. The interaction between maternal antenatal depression and this xPRS accounted for a larger proportion of the variance in child emotional/behavioral problems than models based on any $\operatorname{PRS}_{\mathrm{ADHD}}\left(p=5.50 \times 10^{-9}, R^{2}=.27\right)$, with similar findings in the replication cohort. The xPRS was significantly enriched for genes involved in neuronal development and synaptic function. Our study illustrates a novel approach to the study of genotypic moderation on the impact of maternal antenatal depression on child mental health and highlights the utility of the xPRS approach. These findings advance our understanding of individual differences in the developmental origins of mental health.
\end{abstract}

Keywords: ADHD, child development, gene by environment $(\mathrm{GxE})$, perinatal mental health, polygenic risk score

In this Special Issue article on "Early Adversity, Stress and Neurobehavioral Development" we focus on adversity during one of the most dynamic epochs of human brain development, the antenatal period. Children exposed to antenatal maternal depression are at greater risk for childhood mental disorders (O’Donnell, Glover, Barker, \& O’Connor, 2014; Pearson et al., 2013). However, the effect of maternal antenatal depression on child mental health shows considerable inter-individual variation such that we currently lack the ability to identify the children at greatest risk (Plomin \& Simpson, 2013), which precludes targeted intervention. Here, we seek to better describe the interplay

Author for Correspondence: Kieran J. O’Donnell, Yale Child Study Center, 230 South Frontage Road, New Haven, CT 06519, USA. Email: kieran.odonnell@yale.edu

Cite this article: Chen LM et al (2020). Maternal antenatal depression and child mental health: Moderation by genomic risk for attention-deficit/hyperactivity disorder. Development and Psychopathology 32, 1810-1821. https://doi.org/10.1017/ S0954579420001418 between maternal antenatal depression and child genomic variation to understand the prenatal origins of individual differences in neurobehavior and mental health.

There is now considerable evidence for the importance of genotypic variation as a moderator of the impact of early life adversity on neurodevelopmental outcomes as well as the treatment outcomes of interventions (e.g., Belsky et al., 2009; Brody, Yu, \& Beach, 2015; Cicchetti, Toth, \& Handley, 2015; Ellis, Boyce, Belsky, Bakermans-Kranenburg, \& van IJzendoorn, 2011; Manuck \& McCaffery, 2014; Rutter, 2007; van Ijzendoorn \& Bakermans-Kranenburg, 2015). Several candidate gene analyses (e.g., brain-derived neurotrophic factor $[B D N F]$, catecholO-methyltransferase [COMT], dopamine receptor D4 [DRD4], solute carrier family C6, member 4 [SLC6A4]) suggest child genetic variation may moderate the associations between multiple forms of antenatal maternal "distress" and child emotional/behavioral development (Babineau et al., 2015; Graffi et al., 2017; O’Donnell, Glover, Holbrook, \& O’Connor, 2014; O’Donnell 
et al., 2017). Some of these associations have been replicated in independent samples (e.g., O’Donnell et al., 2017). However, the single candidate gene-by-environment $(\mathrm{GxE})$ approach suffers from well-documented limitations (see Border et al., 2019; Duncan, Pollastri, \& Smoller, 2014; Ficks \& Waldman, 2009 for discussion) and commonly accounts for only a small proportion of the variance in complex phenotypes (O'Donnell et al., 2017; Sullivan, Daly, \& O’Donovan, 2012; Visscher, Hill, \& Wray, 2008). Likewise, previous studies have not examined the nature of the interaction between maternal antenatal depression and child genotype. A subgroup of children, carrying specific genotypes, may be more vulnerable to the effects of antenatal maternal depression; that is, a diathesis-stress model. Alternatively, in children carrying the same genotype, the presence or absence of maternal antenatal depression may associate with increased or decreased risk of disorder, respectively; that is, a differential susceptibility model (Belsky, 1997; Belsky, Bakermans-Kranenburg, \& van IJzendoorn, 2007; Belsky et al., 2009; Belsky, Pluess, \& Widaman, 2013; Pluess \& Belsky, 2009; Roisman et al., 2012). A more thorough understanding of the nature of the interaction between maternal antenatal depression and child genetic variation may help better predict who is likely to benefit from intervention programs that target maternal antenatal depression to improve child outcome. These intervention programs thus far show modest effects on measures of child neurodevelopment (Goodman, Cullum, Dimidjian, River, \& Kim, 2018).

Large-scale initiatives such as the Psychiatric Genomics Consortium and the Social Science Genetic Association Consortium are beginning to define the genetic architecture of individual differences in complex phenotypes (Rietveld et al., 2013; Sullivan et al., 2018), including child neurodevelopmental disorders such as attention-deficit/hyperactivity disorder (ADHD) (Demontis et al., 2019; Martin et al., 2018; Neale et al., 2010). For example, ADHD shares genetic risk factors with at least four other common psychiatric disorders - depression, schizophrenia, autism, and bipolar disorder (Cross-Disorder Group of the Psychiatric Genomics Consortium, 2013). These findings suggest that genetic variants associated with ADHD may have pleiotropic effects on psychopathology as well as specific predictive value for ADHD (Brikell et al., 2020; Du Rietz et al., 2018; Martin, Hamshere, Stergiakouli, O’Donovan, \& Thapar, 2014; Stergiakouli et al., 2015, 2017). This hypothesis is also supported by clinical observations that find childhood ADHD to be comorbid with a range of childhood mental disorders (Biederman, Newcorn, \& Sprich, 1991), as well as the heterotypic continuity observed across common childhood-onset mental disorders (Shevlin, McElroy, \& Murphy, 2017).

Existing genome-wide association studies (GWAS) typically identify a large number of genetic variants, each with a small effect on disease risk. A polygenic risk score (PRS) represents an aggregate score of the additive effects of a number of single nucleotide polymorphisms (SNPs) that collectively contribute to the genomic risk for a given phenotype (Wray, Goddard, \& Visscher, 2007; Wray et al., 2014). These scores can be used to segregate cases from controls and provide a relatively simple measure of the direct effects; that is, main effects of genomic variation for risk of a given disorder (Brikell et al., 2020; Cross-Disorder Group of the Psychiatric Genomics Consortium, 2013; Groen-Blokhuis et al., 2014; Martin et al., 2014; Stergiakouli et al., 2015, 2017). Few studies have examined how variation across the genome (genomic variation) may moderate the impact of maternal antenatal depression on child outcomes and no study to date has examined if the effects of maternal antenatal depression on child mental health symptoms are moderated by genomic variation in the child (although see Pearson et al., 2016, Qiu et al., 2017; Sfelinioti \& Livaditis, 2017).

One of the challenges of using PRS in GxE designs is the inherent "main effects" bias within PRS: these scores are based on SNPs with main effects on a given phenotype and only a subset of these SNPs may contribute to any interaction effect. Alternatively, quantifying interaction effects between a predictor of interest and each SNP within the human genome, a so-called Genome-wide $\times$ Environment interaction analysis, requires very large cohorts (Dunn et al., 2016; Van der Auwera et al., 2018). We propose an alternative approach, one that refines a conventional PRS to retain only those SNPs that interact with an exposure of interest to predict an outcome of interest. We refer to these novel genomic predictors as interaction PRS (xPRS). In this study, we highlight the utility of xPRS to better understand individual differences in the impact of maternal antenatal depression on child emotional/behavioral difficulties in two independent cohorts.

\section{Method and materials}

\section{Cohorts}

\section{Cohort 1}

The Maternal Adversity, Vulnerability and Neurodevelopment (MAVAN) project is a longitudinal birth cohort in Montreal and Hamilton, Canada that examines the influence of the early environment on child development (O'Donnell et al., 2014). We used a subsample $(n=187)$ of 496 mother-child dyad participants in MAVAN for which complete data were available for child genotyping, maternal mental health, and child mental health outcomes (an overview of this cohort is provided in O'Donnell et al., 2014). Institutional approval for this study was obtained from the Douglas Hospital Research Centre, Montreal and St. Joseph Healthcare, Hamilton (protocol number IUSMD-03-45/IUSMD-06-09).

\section{Cohort 2}

The "Basal Influences on Baby Development" (in Dutch: "Basale Invloeden op de Baby Ontwikkeling" - BIBO) study is an ongoing longitudinal community-based birth cohort in the Netherlands (see Beijers, Jansen, Riksen-Walraven, \& de Weerth, 2010 for more information). Measures of maternal mental health, child outcomes, and child genetic variation were available on 132 children. Institutional approval for the BIBO cohort was obtained from the Faculty of Social Sciences of Radboud University (\#ECG300107).

\section{Child mental health}

Child mental health symptoms were assessed via maternal report using the Child Behavior Checklist (CBCL) at 60 months postpartum (Achenbach, 1991). The total score was further refined to describe internalizing or externalizing symptoms. Internalizing problems included emotional reactive symptoms, anxious/ depressed symptoms, somatic complaints, and withdrawn behaviors. The externalizing problems included inattention and aggressive behaviors. In the BIBO cohort, the Dutch CBCL (Verhulst, Akkerhuis, \& Althaus, 1985) was completed by mothers at 72 months postpartum. The internalizing problems included 
anxious/depressed symptoms, somatic complaints, and withdrawn behaviors. The externalizing problems included delinquent and aggressive behaviors.

\section{Maternal depression}

Mothers in the MAVAN cohort completed the Center for Epidemiologic Studies Depression Scale (CES-D) (Radloff, 1977) to assess symptoms of depression. CES-D scores were available during the third trimester of pregnancy $\left(\mathrm{CES}-\mathrm{D}_{\mathrm{pre}}\right)$ and at 12 months $\left(\mathrm{CES}-\mathrm{D}_{12 \mathrm{mths}}\right)$ and 60 months postpartum (CES- $\left.\mathrm{D}_{60 \mathrm{mths}}\right)$. In the $\mathrm{BIBO}$ cohort, maternal depression was assessed using the Dutch version of the Edinburgh Postnatal Depression Scale (EPDS) (Cox, Holden, \& Sagovsky, 1987; Pop, Komproe, \& van Son, 1992) during the third trimester of pregnancy $\left(\mathrm{EPDS}_{\text {pre }}\right)$ and at 72 months postpartum (EPDS $\left.{ }_{72 \mathrm{mths}}\right)$.

\section{Genotyping, quality control, and imputation}

We used the PsychChip (v1) or PsychArray (v1.1) (Illumina, Inc.) to assess genomic variation in children within the MAVAN cohort. Samples with low call rates $(<90 \%)$ and probes with low sample call rates $(<95 \%)$ or that deviated from HardyWeinberg equilibrium $\left(p<1 \times 10^{-11}\right)$ were removed during quality control. Genome-wide imputation was performed using the Sanger Imputation Service (McCarthy et al., 2016) on autosomal SNPs with minor allele frequency $(\mathrm{MAF}) \geq 5 \%$. The Haplotype Reference Consortium (release 1.1) was used as the reference panel (McCarthy et al., 2016). Imputed SNPs with low imputation accuracy (info score $\leq 0.8$ ), multi-allelic SNPs, and palindromic SNPs were removed prior to PRS computation. Overall, 17,703,929 autosomal SNPs were available for our analyses.

We used the Infinium Global Screening Array (Illumina, Inc.) to assess genomic variation in children within the BIBO cohort. Samples and probes with low call rates $<95 \%$, deviated from Hardy-Weinberg equilibrium $\left(p<1 \times 10^{-20}\right.$ ), or MAF $<5 \%$ were removed during quality control. We used the Sanger Imputation Service (McCarthy et al., 2016) to impute autosomal SNPs against the Haplotype Reference Consortium (release 1.1) providing 23,037,776 autosomal SNPs for our analyses.

\section{Conventional polygenic risk score calculation}

PRSs are derived using a count function of risk alleles with each allele weighted by its association with the risk of disorder (Chen et al., 2018). These effect-size estimates and associated summary statistics are provided by an independent, existing GWAS. PRSs for $\mathrm{ADHD}\left(\mathrm{PRS}_{\mathrm{ADHD}}\right)$ were computed using the summary statistics from a GWAS of ADHD by the Psychiatric Genomics Consortium (Neale et al., 2010) and not the more recent GWAS of ADHD carried out by Demontis et al. (2019). We chose this approach based on findings from the MAVAN cohort, which revealed a stronger prediction of an objective measure of child ADHD using a PRS based on the findings from the Neale et al. study (Demontis et al., 2019; Neale et al., 2010) (See Supplementary Appendix A: Figure S1). All subsequent analyses focus on $\mathrm{PRS}_{\mathrm{ADHD}}$ informed by the findings from Neale et al. (2010). SNPs were pruned using the $p$ value informed clumping function in PLINK 1.9 (Chang et al., 2015), which removed SNPs in high linkage disequilibrium $\left(r^{2}>.2\right)$ across a 500 kilobase regions, retaining a single sentinel SNP for a given region (Neale et al., 2010). PRS $_{\text {ADHD }}$ was computed at $p$ value thresholds between
0.01 and 1.00 at intervals of 0.01 using PRS-on-Spark (Chen et al., 2018) and adjusted for measures of population stratification (see Supplementary Appendix A: Supplementary Methods and Figure S2) (Patterson, Price, \& Reich, 2006; Price et al., 2006).

\section{Statistical analysis}

All statistical analyses were performed using R (https://cran.r-project.org). CBCL and CES-D scores in MAVAN were square-root transformed and the CBCL scores in BIBO were log transformed to satisfy assumptions for linear regression analysis.

\section{Conventional PRS and child mental health}

We defined the "Best-Fit" child PRS $_{\mathrm{ADHD}}$ as the $\mathrm{PRS}_{\mathrm{ADHD}}$ (at a given $p$ value threshold) that interacted with maternal CES- $D_{\text {pre }}$ to account for the largest proportion of variance (i.e., highest $R^{2}$ ) in child outcome (see Equation 1). All models of child emotional/behavioral problems were adjusted for concurrent maternal depressive symptoms to avoid potential bias in the report of child outcomes (van der Toorn et al., 2010). The addition of gender to the model did not improve model fit and was not considered in subsequent analyses (see Supplementary Appendix A for further information).

\section{Best-Fit Model:}

$$
\mathrm{CBCL} \sim \mathrm{PRS}_{\mathrm{ADHD}}+\mathrm{CES}-\mathrm{D}_{\text {pre }}+\mathrm{PRS}_{\mathrm{ADHD}} \times \mathrm{CES}-\mathrm{D}_{\text {pre }}+\mathrm{CES}-\mathrm{D}_{60 \mathrm{mths}}
$$

\section{Interaction polygenic risk scores and child outcomes}

We used linear models (Equation 2) to identify individual SNPs $\left(\mathrm{SNP}_{\mathrm{i} . . . \mathrm{j}}\right)$ within the Best-Fit PRS $\mathrm{ADHD}_{\text {that }}$ thoderate the association between maternal CES- $D_{\text {pre }}$ and child outcome:

Single SNP Interaction Model:

$$
\mathrm{CBCL} \sim \mathrm{SNP}_{\mathrm{i} . . \mathrm{j}}+\mathrm{CES}-\mathrm{D}_{\text {pre }}+\mathrm{SNP}_{\mathrm{i} . . \mathrm{j}} \times \mathrm{CES}-\mathrm{D}_{\text {pre }}+\mathrm{CES}-\mathrm{D}_{60 \mathrm{mths}}
$$

\section{Interaction PRS (XPRS)}

Next, we constructed a novel PRS based on SNPs that moderate the association between maternal CES- $\mathrm{D}_{\text {pre }}$ and child outcome, which we term an interaction PRS (xPRS). We generated xPRS at a range of $p$ value thresholds (i.e., the $p$ value for the interaction term between each SNP and CES-D pre from Equation 2) such that distinct $x$ PRS consisted of different numbers of SNPs. Likewise, each SNP within the xPRS was weighted by the ADHD-associated effect-size estimates from the discovery GWAS (Neale et al., 2010). Finally, xPRSs were adjusted for population stratification. In line with our analyses of the conventional PRS ${ }_{\mathrm{ADHD}}$, we examined the interaction between maternal CES- $D_{\text {pre }}$ and xPRS calculated at a range of thresholds $(p \leq .01-p \leq 1.00)$. We defined the "Best-Fit" xPRS as the xPRS that moderated the association between maternal CES- $D_{\text {pre }}$ and child CBCL scores and accounted for the largest proportion of the variance in the child outcome (see Equation 3):

Best-Fit xPRS Model:

$\mathrm{CBCL} \sim \mathrm{xPRS}+\mathrm{CES}-\mathrm{D}_{\text {pre }}+\mathrm{xPRS} \times \mathrm{CES}-\mathrm{D}_{\text {pre }}+\mathrm{CES}-\mathrm{D}_{60 \mathrm{mths}}$

SNPs that contributed to the Best-Fit xPRS in MAVAN were used to compute the xPRS in the BIBO cohort and the resulting $\mathrm{xPRS}$ was adjusted for population stratification. 
xPRS Replication (BIBO):

$\mathrm{CBCL} \sim \mathrm{xPRS}+\mathrm{EPDS}_{\text {pre }}+\mathrm{xPRS} \times \mathrm{EPDS}_{\text {pre }}+\mathrm{EPDS}_{72 \mathrm{mths}}$

\section{Cross-validation analysis}

We performed a leave-one-out cross-validation (LOOCV) in MAVAN using the caret package in $\mathrm{R}$ (Kuhn, 2008). We compared the predictive accuracy of three separate models: Model 1: a main effects model (see Equation 5), which simply tested the predictive accuracy of an additive model that considered CES-D $D_{\text {pre }}, C E S-D_{60 m t h s}$ and child PRS $_{\mathrm{ADHD}}$ to predict child CBCL scores; Model 2: an interaction model (equivalent to Equation 1) and Model 3: an xPRS interaction model (equivalent to Equation 3). Root-mean-square error (RMSE) was used to measure the average prediction error across models.

LOOCV Main effects:

$$
\mathrm{CBCL} \sim \mathrm{PRS}_{\mathrm{ADHD}}+\mathrm{CES}-\mathrm{D}_{\text {pre }}+\mathrm{CES}-\mathrm{D}_{60 \mathrm{mths}}
$$

Diathesis-stress versus differential susceptibility models of child outcome

We calculated three different metrics that can be used to evaluate if an interaction supports a diathesis-stress or differential susceptibility model (Roisman et al., 2012). These metrics included the regions of significance (RoS), the proportion of interaction (PoI), and the percentage affected (PA) index. RoS refer to the range of values of the predictor (i.e., maternal antenatal symptoms of depression) where the outcomes (i.e., child mental health symptoms) are significantly different between those scoring high or low on the moderator (i.e., child xPRS). Differential susceptibility is supported if the upper and lower bound of the RoS fall within two standard deviations of the mean of the predictor. The PoI measures the total area between the lines of an interaction plot above the cross-over point. PoI values ranging from 0.40-0.60 support differential susceptibility, while a value of 0.00 provides clear evidence of diathesis-stress. Finally, the PA refers to the percentage of individuals within the cohort who fall above the cross-over point for a given interaction plot. Differential susceptibility is supported if the PA is greater than 16\% (Roisman et al., 2012).

\section{Enrichment analysis}

We mapped SNPs from our Best-Fit xPRS to their corresponding genes and performed gene ontology (GO) enrichment analysis using MetaCore ${ }^{\circledast}$ (Thomson Reuters). The genes identified from SNPs within the conventional child $\mathrm{PRS}_{\mathrm{ADHD}}$ were set as the background gene list for this analysis. We only reported the significant (False Discovery Rate $\leq 5 \%$ ) top-ranked biological processes and cell components from this analysis.

\section{Results}

\section{Demographics}

Table 1 shows the demographic information as well as the maternal and child measures for each cohort.

\section{Maternal antenatal depression and child mental health}

We examined the correlation between child CBCL scores at 60 months and predictors of interest (Table 2). Maternal depression
Table 1. Cohort demographics. Mean and standard deviations are presented

\begin{tabular}{lll}
\hline & Cohort 1 MAVAN & Cohort 2 BIBO \\
\hline$N$ & 187 & 132 \\
\hline Ethnicity & & \\
\hline Caucasian & $82 \%$ & $100 \%$ \\
\hline Mixed Caucasian & $11 \%$ & \\
\hline Non-Caucasian & $7 \%$ & $47 \%$ \\
\hline Child Gender (female \%) & $52 \%$ & $32.8 \pm 3.9$ \\
\hline Maternal age at birth (years) & $30.7 \pm 4.9$ & $5.3 \pm 3.9$ \\
\hline Maternal depressive symptoms ${ }^{\mathrm{a}}$ & & $\mathrm{N} / \mathrm{A}$ \\
\hline Pregnancy & $11.7 \pm 9.4$ & $4.0 \pm 3.1$ \\
\hline 12 months postpartum & $10.2 \pm 8.4$ & \\
\hline Child's mid-childhood & $10.1 \pm 8.2$ & $10.6 \pm 7.4$ \\
\hline CBCL at mid-childhood & & $4.1 \pm 3.9$ \\
\hline Total score & $27.1 \pm 18.2$ & $6.5 \pm 5.0$ \\
\hline Internalizing score & $8.3 \pm 6.6$ & \\
\hline Externalizing score & $9.4 \pm 6.9$ & \\
\hline
\end{tabular}

${ }^{a}$ Maternal symptoms of depression were measured using Center for Epidemiologic Studies Depression Scale (CES-D: MAVAN) or the Edinburgh Postnatal Depression Scale (EPDS: BIBO). MAVAN = Maternal Adversity, Vulnerability and Neurodevelopment; BIBO = Basal Influences on Baby Development" (in Dutch: "Basale Invloeden op de Baby Ontwikkeling" - BIBO)

Table 2. Correlations between child mental health symptoms at 60 months and predictors of interest in the Maternal Adversity, Vulnerability and Neurodevelopment (MAVAN) cohort

\begin{tabular}{|c|c|c|c|}
\hline & $\begin{array}{c}\text { Total } \\
\text { problems }\end{array}$ & $\begin{array}{l}\text { Internalizing } \\
\text { problems }\end{array}$ & $\begin{array}{c}\text { Externalizing } \\
\text { problems }\end{array}$ \\
\hline $\begin{array}{l}\text { CES-D pre } \\
(n=187)\end{array}$ & $\begin{array}{l}r_{p}=.260 \\
p=3.18 \times 10^{-4}\end{array}$ & $\begin{array}{l}r_{p}=.252 \\
p=5.14 \times 10^{-4}\end{array}$ & $\begin{array}{l}r_{p}=.147 \\
p=.04\end{array}$ \\
\hline $\begin{array}{l}\text { CES-D } 12 \text { mths } \\
(n=180)\end{array}$ & $\begin{array}{l}r_{p}=.287 \\
p=9.50 \times 10^{-5}\end{array}$ & $\begin{array}{l}r_{p}=.180 \\
p=.02\end{array}$ & $\begin{array}{l}r_{p}=.299 \\
p=4.58 \times 10^{-5}\end{array}$ \\
\hline $\begin{array}{l}\text { CES-D } 60 \text { mths } \\
(n=187)\end{array}$ & $\begin{array}{l}r_{p}=.387 \\
p=4.39 \times 10^{-8}\end{array}$ & $\begin{array}{l}r_{p}=.316 \\
p=1.06 \times 10^{-5}\end{array}$ & $\begin{array}{l}r_{p}=.351 \\
p=8.39 \times 10^{-7}\end{array}$ \\
\hline $\begin{array}{l}\text { Maternal smoking } \\
(n=186)\end{array}$ & $\begin{array}{l}r_{s}=-.019 \\
p=.80\end{array}$ & $\begin{array}{l}r_{s}=.010 \\
p=.90\end{array}$ & $\begin{array}{l}r_{s}=-.025 \\
p=.73\end{array}$ \\
\hline $\begin{array}{l}\text { Maternal alcohol use } \\
(n=185)\end{array}$ & $\begin{array}{l}r_{s}=-.020 \\
p=.79\end{array}$ & $\begin{array}{l}r_{s}=.071 \\
p=.33\end{array}$ & $\begin{array}{l}r_{s}=-.045 \\
p=.54\end{array}$ \\
\hline $\begin{array}{l}\text { Child birthweight } \\
(n=187)\end{array}$ & $\begin{array}{l}r_{p}=-.060 \\
p=.42\end{array}$ & $\begin{array}{l}r_{p}=-.100 \\
p=.17\end{array}$ & $\begin{array}{l}r_{p}=-.021 \\
p=.78\end{array}$ \\
\hline $\begin{array}{l}\text { Child gender } \\
(n=187)\end{array}$ & $\begin{array}{l}r_{s}=.021 \\
p=.78\end{array}$ & $\begin{array}{l}r_{s}=.035 \\
p=.64\end{array}$ & $\begin{array}{l}r_{s}=-.038 \\
p=.60\end{array}$ \\
\hline
\end{tabular}

Maternal depression scores during pregnancy (CES- $\left.D_{\text {pre }}\right)$, at 12 months (CES- $D_{12 m}$ ths $)$, and at 60 months (CES- $\left.D_{60 m t h s}\right)$ were significantly correlated with child internalizing, externalizing and total problem scores. $r_{p} / r_{s}=$ Pearson/Spearman correlation coefficients.

symptom scores across all time points were consistently associated with child internalizing, externalizing, and total problem scores (Table 2). CBCL scores did not differ between boys and girls (total problems: $t_{(185)}=-0.129, p=.90$; internalizing problems: $t_{(185)}=-0.381, p=.70$; externalizing problems: $t_{(185)}=0.482, p=.63$ ).

\section{Moderation by $P R S_{A D H D}$}

Child PRS ${ }_{\mathrm{ADHD}}$ (at $p$ value thresholds $p \geq .01$ ) moderated the association between maternal CES- $\mathrm{D}_{\text {pre }}$ and CBCL total problem 


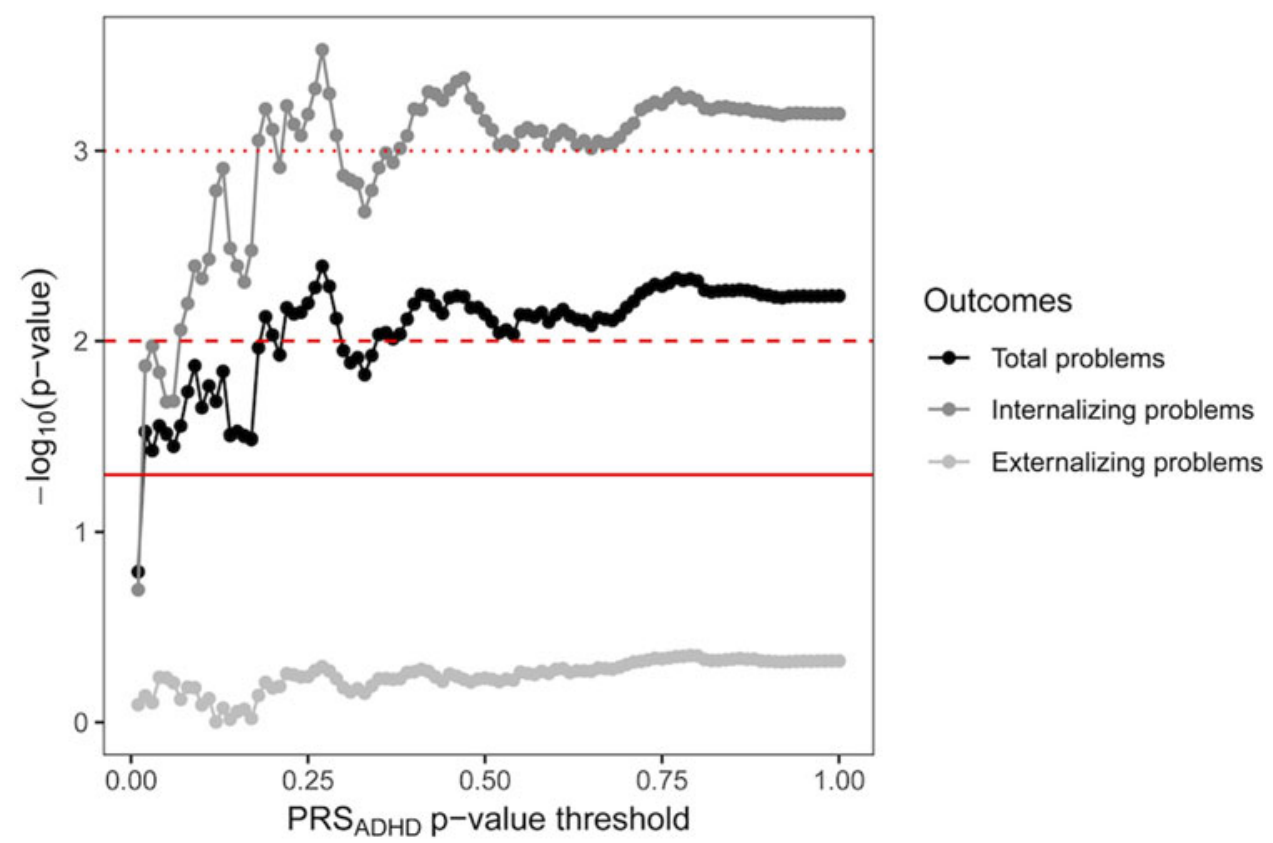

Figure 1. $p$ value curve plot for models testing the interaction between child polygenic risk scores for attention-deficit/hyperactivity disorder (PRS $\mathrm{ADHD}_{\mathrm{B}}$ ) and mater-

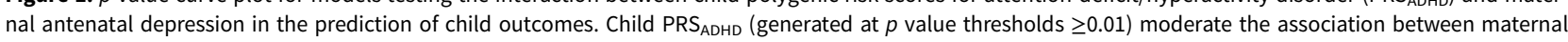
antenatal depression and child total problems (black line) and internalizing problems (gray line) but not externalizing problems (light gray line). Horizontal lines correspond to $p=.05$ (solid line), $p=.01$ (dashed line), $p=.001$ (dotted line).

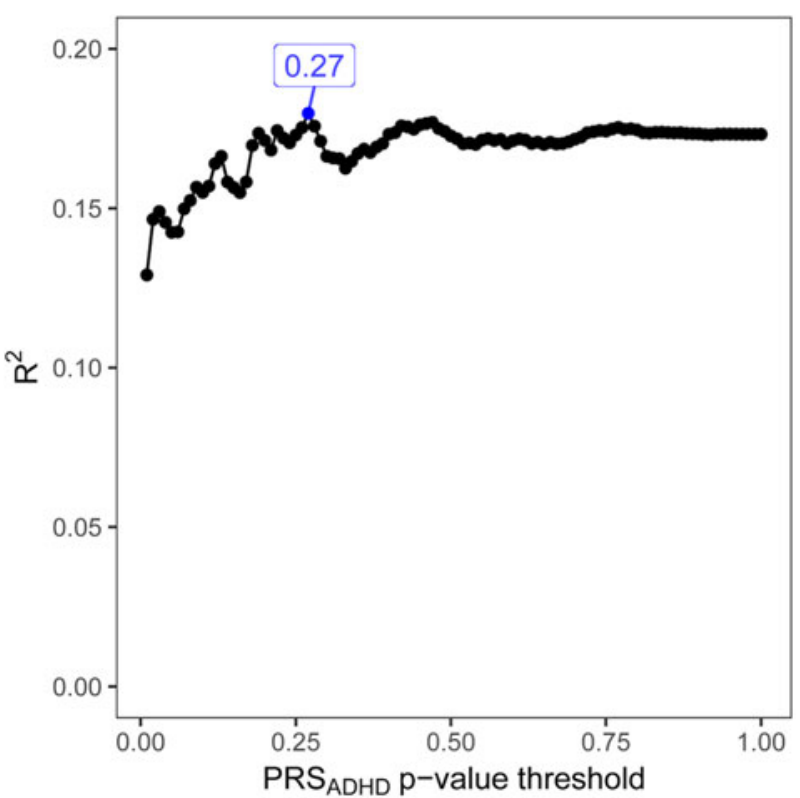

Figure 2. Variance explained $\left(R^{2}\right)$ by models considering interactions between child polygenic risk scores for attention-deficit/hyperactivity disorder $\left(\mathrm{PRS}_{\mathrm{ADHD}}\right)$ and maternal antenatal depression in the prediction of child internalizing problems. The label at $p=.27$ indicates the $\operatorname{PRS}_{\mathrm{ADHD}} p$ value threshold that explains the highest proportion of variance in child internalizing symptoms (i.e., the Best-Fit $P_{R S}{ }_{A D H D}$ ).

scores (Figure 1 and Supplementary Appendix A Figure S3). There was a significant interaction between child $\mathrm{PRS}_{\mathrm{ADHD}}$ and maternal CES- $D_{\text {pre }}$ scores in prediction of internalizing problems, but not externalizing problems (see Figure 1 and Supplementary Appendix A Figure S3). An interaction model that considered maternal antenatal depressive symptoms and a $\mathrm{PRS}_{\mathrm{ADHD}}$ at $p$ value threshold of $p=.27$ accounted for the largest proportion of variance in child internalizing symptoms $\left(R^{2}=.18, F_{(4,182)}=\right.$ 9.97, $p=2.55 \times 10^{-7}$; Figures 2 and Supplementary Appendix A Figure S3). This Best-Fit PRS ${ }_{\mathrm{ADHD}}$ consisted of 59,683 independent SNPs. Children with a higher PRS $\mathrm{ADHD}_{\mathrm{AD}}$ born to women with higher symptoms of antenatal depression had a greater number of internalizing symptoms (interaction term: beta $=0.283, p=2.94 \times$ $10^{-4}$; Figure 3 ). To test if this finding was robust, we considered potential interactions between our exposure (maternal antenatal depressive symptom scores), our moderator $\left(\mathrm{PRS}_{\mathrm{ADHD}}\right)$ and all covariates in our model following recommendations by Keller (2014). Our results were largely unchanged (see Supplementary Appendix A: Tables S1 and S2).

\section{Moderation by XPRS}

Child PRS $\mathrm{ADHD}_{\mathrm{A}}$ significantly moderated the association between maternal symptoms of antenatal depression and child CBCL problem scores. We then sought to create a PRS specific for this interaction effect. We thus examined the interaction between maternal antenatal depressive symptom scores and each SNP within our Best-Fit $\mathrm{PRS}_{\mathrm{ADHD}}\left(\mathrm{PRS}_{\mathrm{ADHD}} p\right.$ value threshold $=$ 0.27 , with 59,683 SNPs) and generated xPRS at a number of different $p$ value thresholds (ranging from $p \leq .01$ to $p \leq 1.00$, see Method). An xPRS generated from SNPs with an interaction $p$ value $\leq 0.14(13,835$ SNPs) accounted for the largest proportion of variance in child outcomes consisted of $\left(R^{2}=.272, F_{(4,182)}=\right.$ 17.036, $p=6.96 \times 10^{-12}$; Figure $\left.4 \mathrm{~b}\right)$ and was deemed the Best-Fit $x P R S$. In contrast, an xPRS generated from SNPs with an interaction $p$ value $\leq 0.05$ (i.e., SNPs with a significant interaction term, $n=6,711$ SNPs) accounted for a much smaller proportion of the variance in child internalizing symptoms $\left(R^{2}=.221, F_{(4,182)}=\right.$ 12.87, $\left.p=3.00 \times 10^{-9}\right)$, highlighting the increased predictive power of the Best-Fit xPRS, which included nominally significant SNPs and SNPs with more modest interaction effects. 


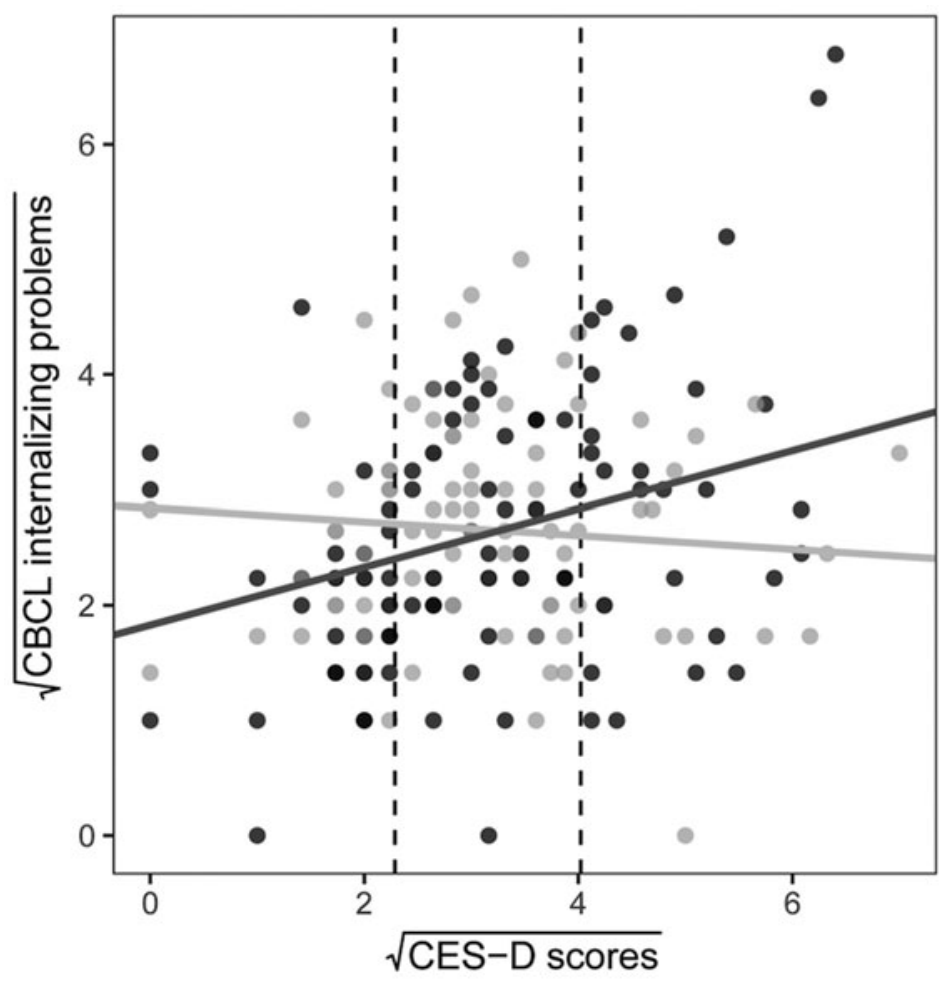

\section{PRS $_{A D H D}$}

- High PRS

- Low PRS

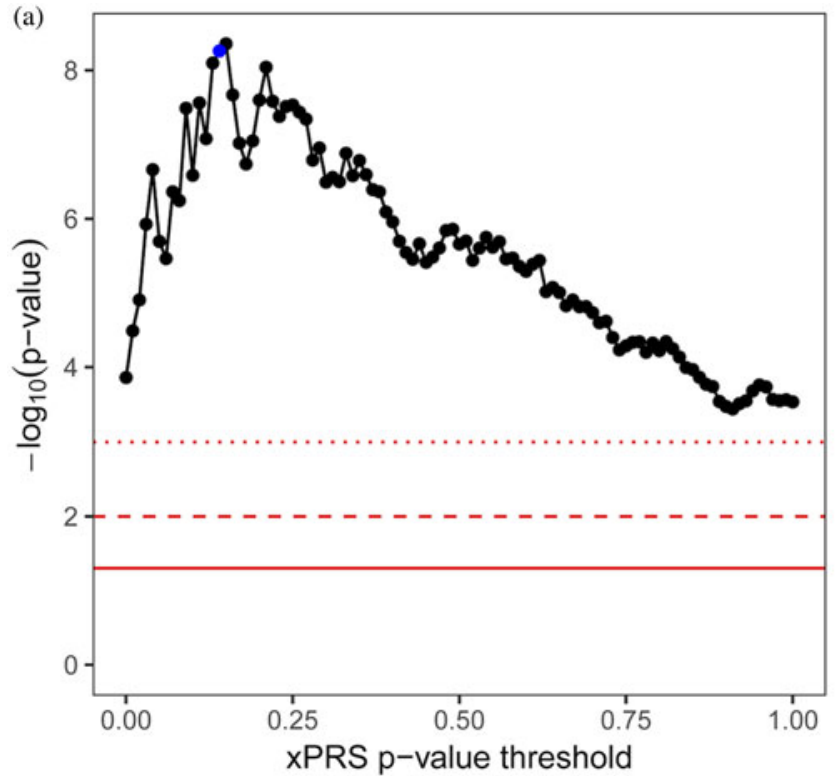

(a)

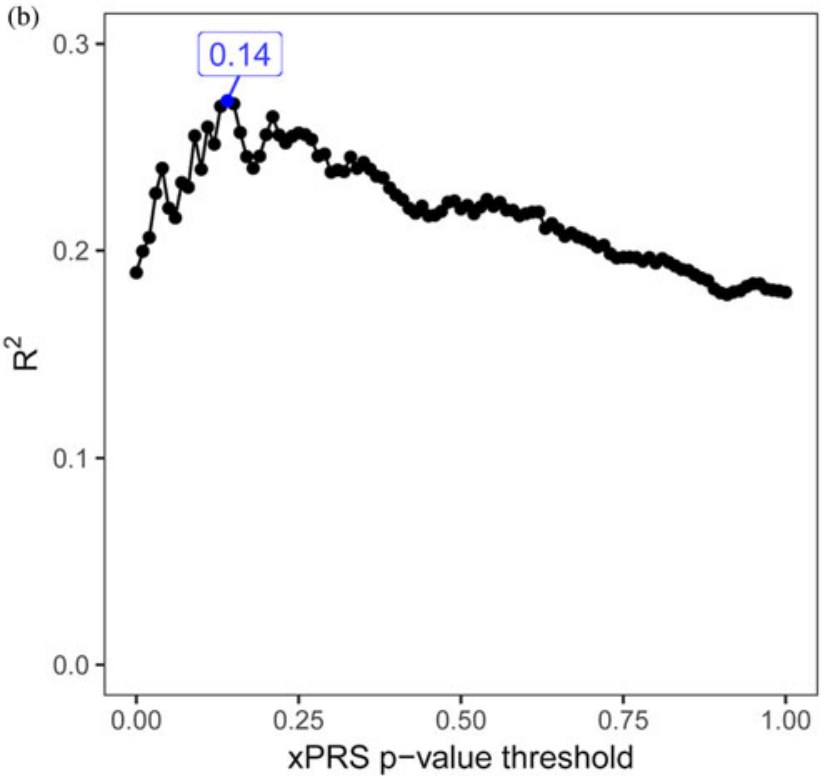

(b)

Figure 4. Interaction-based polygenic risk score (xPRS) model selection. $p$ value curve plot of models testing the interaction between $\mathrm{xPRS}$ at different $p$ value thresholds and maternal antenatal depression in the prediction of child internalizing problems (a). $R^{2}$ curve plot of models testing the interaction between xPRS at different $p$ value thresholds and maternal antenatal depression in the prediction of child internalizing problems (b). The label and point indicate the $\mathrm{xPRS} p$ value threshold that accounted for the largest proportion of variance (i.e., the Best-Fit xPRS). Horizontal lines correspond to $p=.05$ (solid line), $p=.01$ (dashed line), $p=.001$ (dotted line).

Children with a higher xPRS born to women with a higher antenatal depressive symptom score had a greater number of internalizing problems (interaction term: beta $=0.335, p=5.50 \times 10^{-9}$; Figure 5).
Figure 3. The Best-Fit polygenic risk score for attention-deficit/hyperactivity disorder $\left(\mathrm{PRS}_{\mathrm{ADHD}}\right)$ significantly moderates the relationship between maternal antenatal depression and child internalizing problems. Maternal symptoms of depression (CES-D scores) predict higher internalizing symptoms in children with higher ADHD polygenic risk scores (visualized using a median split). Regions of significance are depicted outside the vertical dotted lines. $\quad \mathrm{CBCL}=$ Child Behavior Checklist, $C E S-D=$ Center for Epidemiologic Studies Depression Scale. 
Figure 5. The Best-Fit interaction-based polygenic risk score (xPRS) significantly moderates the relationship between maternal antenatal depressive symptoms and child internalizing problems. Maternal symptoms of depression (CES-D scores) predict higher internalizing symptoms in children with a higher xPRS (visualized using a median split). Regions of significance are depicted outside the vertical dotted lines. $\mathrm{CBCL}=$ Child Behavior Checklist, CES-D = Center for Epidemiologic Studies Depression Scale.

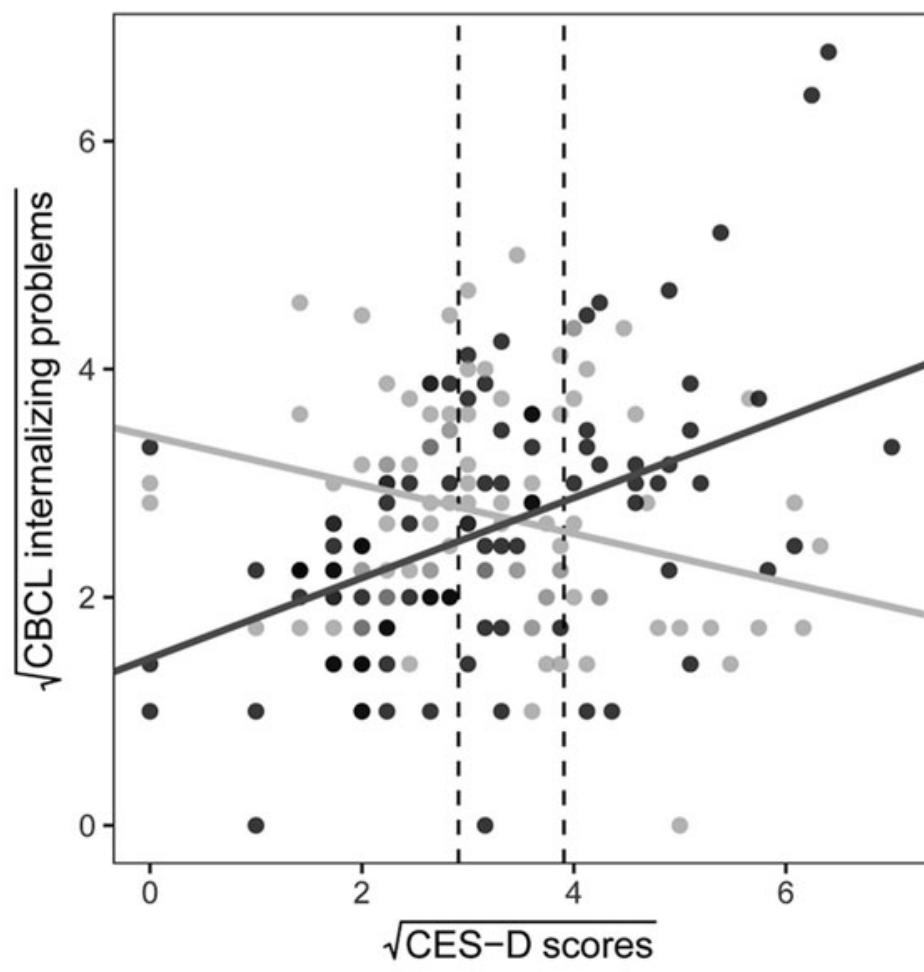

xPRS

- High PRS - Low PRS
Table 3. Leave-one-out cross-validation analyses

\begin{tabular}{|c|c|c|}
\hline Model & RMSE & $R^{2}$ \\
\hline \multicolumn{3}{|l|}{ Model 1} \\
\hline $\mathrm{CBCL}_{\text {INT }} \sim \mathrm{PRS}_{\mathrm{ADHD}}+\mathrm{CES}-\mathrm{D}_{\text {pre }}+\mathrm{CES}-\mathrm{D}_{60 \mathrm{mths}}$ & 1.042 & .082 \\
\hline \multicolumn{3}{|l|}{ Model 2} \\
\hline $\begin{array}{l}\mathrm{CBCL}_{\mathrm{INT}} \sim \mathrm{PRS}_{\mathrm{ADHD}}+\mathrm{CES}-\mathrm{D}_{\text {pre }}+\mathrm{PRS}_{\mathrm{ADHD}} \times \\
\mathrm{CES}-\mathrm{D}_{\text {pre }}+\mathrm{CES}-\mathrm{D}_{60 \mathrm{mths}}\end{array}$ & 1.016 & .128 \\
\hline \multicolumn{3}{|l|}{ Model 3} \\
\hline $\begin{array}{l}C B C L_{\text {INT }} \sim x P R S+C E S-D_{\text {pre }}+x P R S \times C E S-D_{\text {pre }}+ \\
C E S-D_{60 m \text { ths }}\end{array}$ & 0.953 & .230 \\
\hline
\end{tabular}

Competing prediction models of child internalizing symptoms from the Child Behavior Checklist $\left(\mathrm{CBCL}_{\mathrm{INT}}\right)$ were compared using two measures of model fit: the total proportion of variance explained $\left(R^{2}\right)$ and the root-mean-square error (RMSE). CES-D = Center for Epidemiological Studies Depression. xPRS = Interaction polygenic risk score.

symptoms: Model 3, which considered main effects and an interaction term between CES- $\mathrm{D}_{\text {pre }}$ and the xPRS outperformed all other models (Table 3).

\section{Replication analyses}

Ninety-six per cent $(n=13,252)$ of SNPs from the Best-Fit xPRS in the MAVAN sample were available for analysis in the BIBO cohort. In the BIBO cohort the child xPRS significantly moderated the association between maternal depressive symptom scores in pregnancy and child internalizing symptoms at 72 months in the BIBO cohort (beta $=0.02, p=.02$ ), consistent with our findings in the MAVAN cohort. The association between maternal

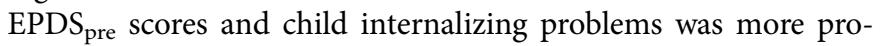
nounced in children with a higher xPRS (Figure 6).

\section{Differential susceptibility versus diathesis-stress}

Table 4 provides RoS, PoI, and PA estimates from prediction models of child internalizing symptoms in the MAVAN (Models A and B) and BIBO (Model C) cohorts. In the MAVAN cohort, the interaction between maternal antenatal symptoms of depression and (a) child $\mathrm{PRS}_{\mathrm{ADHD}}$ or (b) child $x$ PRS provide greater evidence for differential susceptibility than a diathesis-stress model. Specifically, the RoS fall within two standard deviations of mean maternal CES- $D_{\text {pre }}$ scores, the PoI is closer to 0.40 (than 0.00) and the PA is greater than $16 \%$. In the BIBO cohort, the RoS and PA provide support for differential susceptibility. For example, the PA is above $16 \%$ and the lower bound of the RoS falls within two standard deviations of mean antenatal EPDS scores, while the upper bound falls just outside of this two standard deviation range (13.74 vs. 13.04). In contrast, the PoI value in the BIBO cohort (0.06) suggests the relationship between maternal antenatal symptoms of depression, child xPRS and child internalizing symptoms is better explained by a diathesis-stress model.

\section{Gene ontology of XPRS}

Our xPRS analysis identifies SNPs that significantly moderate the association between maternal mental health and child behavioral problems. We interrogated our xPRS by mapping the xPRS SNPs to genes and examining biological functions associated with these genes. This analysis provides insight into candidate neural processes that lie along the pathway linking maternal antenatal mental health to child behavioral problems. Enrichment analysis of the SNPs comprising the Best-Fit xPRS showed a highly significant enrichment for genes associated with synaptic functions and neuronal development (Supplementary Appendix A: Table S3 and Figure S4). The top ten enriched GO cellular 


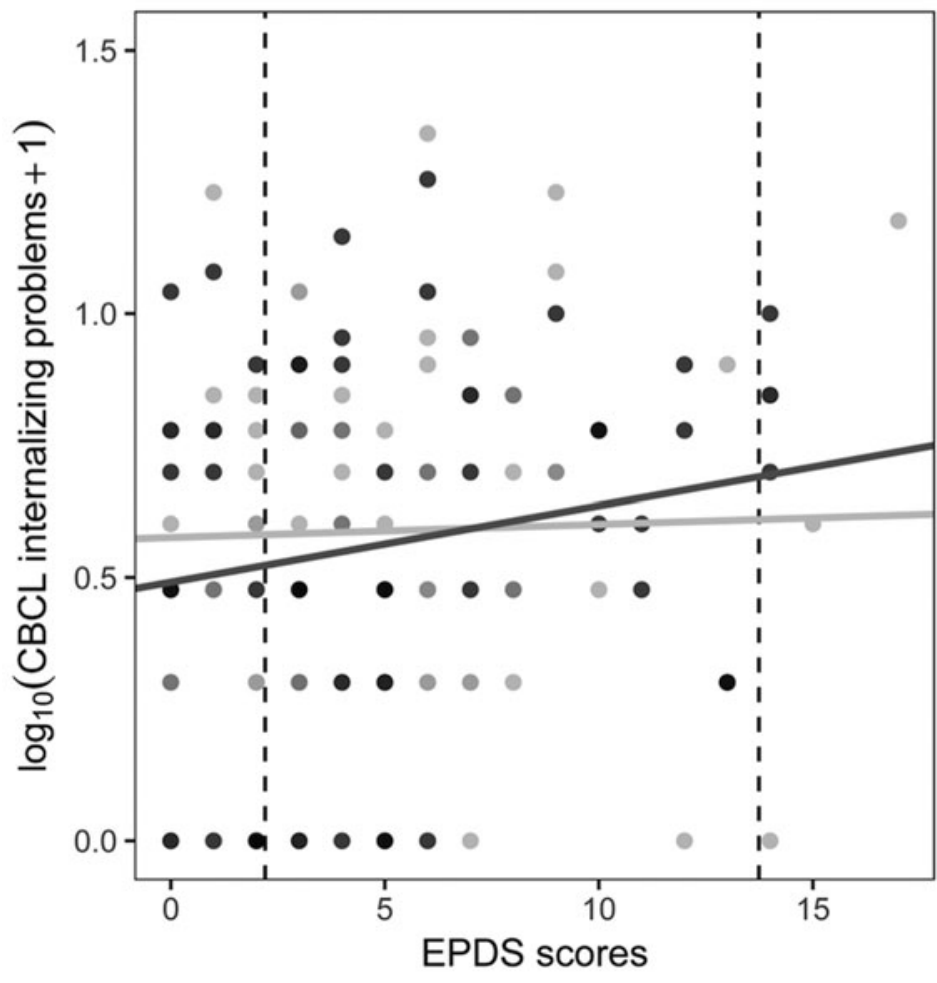

\section{XPRS}

- High PRS

- Low PRS
Table 4. Analysis of the interactions for the Best-Fit polygenic risk score (PRS) interaction models for internalizing problems $\left(C B L_{I N T}\right)$ and the replicated findings

\begin{tabular}{lccc}
\hline Model & RoS & Pol & PA (\%) \\
\hline A & $(2.29,4.02)$ & 0.34 & 57 \\
\hline B & $(2.91,3.91)$ & 0.39 & 61 \\
\hline C & $(2.20,13.74)$ & 0.06 & 70 \\
\hline
\end{tabular}

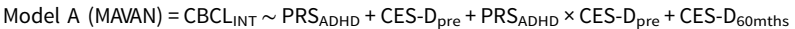
Model $B($ MAVAN $)=C B C L_{\text {INT }} \sim x P R S+C E S-D_{\text {pre }}+x P R S \times C E S-D_{\text {pre }}+C E S-D_{60 \text { mths }}$.

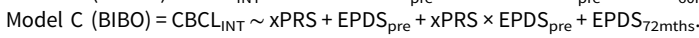
RoS $=$ regions of significance fall below (lower bound) or above (upper bound) the reported interval; Pol = proportion of interaction; $\mathrm{PA}=$ percentage affected.

components can be localized to the "postsynapse" (GO:0098794; $\left.p=5.84 \times 10^{-10}\right)$ and "dendrite" (GO:0030425; $p=8.97 \times 10^{-10}$ ). In addition, genes identified within the xPRS are involved in a number of biological processes related to neurogenesis ("generation of neurons" GO:0048699; $p=9.74 \times 10^{-12}$ ) and cell projection ("regulation of plasma membrane bounded cell projection organization" GO:0120035; $p=1.64 \times 10^{-9}$ ).

\section{Discussion}

The impact of maternal antenatal mental health on child emotional/behavioral outcomes is well documented (Gentile, 2017; Goodman et al., 2011; Meaney, 2018; O’Donnell et al., 2014; Pearson et al., 2013) as are the individual differences observed with such effects. A detailed systematic review revealed that the association between maternal depression and child behavioral problems, while highly reliable across studies, is generally modest (Goodman et al., 2011). Our findings are consistent with the idea that child genotype is an important source of variation. The challenge is that of capturing this genotypic variation beyond proof-of-principal studies with candidate genes. The use of PRSs has provided one approach; however, PRSs are based on genetic main effects, while clinical phenotypes inevitably derive from GxE interactions. PRSs may thus be of limited value for analyses of genotypic moderation of early life adversity (Peyrot et al., 2018 and see below). We outline a novel approach, an interaction-based PRS (xPRS) that better describes child genomic susceptibility to maternal antenatal depression than the conventional PRS approach. We thus leveraged insights from a large-scale GWAS of child neurodevelopment to better understand the individual differences in the impact of maternal antenatal depression on child mental health. In doing so, we find convergent evidence for differential susceptibility in the prediction of child internalizing symptoms as a function of child genomic variation and maternal antenatal depression.

Our findings further underscore the importance of considering child genotype when describing the impact of maternal antenatal mental health on child development (Grizenko et al., 2012; O’Donnell et al., 2017; O’Donnell \& Meaney, 2017; Thompson et al., 2014). Our approach moves beyond candidate gene analyses to consider genetic variants across the genome, prioritizing SNPs identified by a GWAS of child neurodevelopment (Neale et al., 2010). A small number of previous studies used a genome-wide data on genomic variation to understand how prenatal exposures shape child neurodevelopment (e.g., Qiu et al., 2017; Silveira et al., 2017, 2018). Qiu et al. (2017) report that a child's PRS for major depressive disorder (MDD) moderates the association between maternal antenatal depression and amygdala volume in neonates from two independent cohorts. Silveira et al. (2017) show that child genomic variation (SNPs in genes co-expressed with the serotonin transporter) moderates the effect of prenatal adversity on child development, an effect that was not observed when using a candidate 
gene approach. In adults, analyses that consider the interaction of environmental exposures and PRSs show mixed results. Peyrot et al. (2014) find that a PRS for MDD significantly moderates the association between childhood trauma and risk of MDD; individuals with a higher PRS for MDD exposed to childhood trauma show higher rates of MDD. Mullins et al. (2016) observe an interaction between childhood trauma and a PRS for MDD but in the opposite direction; that is, a higher genetic risk predicts lower risk of MDD in individuals with a history of childhood trauma. A larger metaanalysis, which includes both cohorts, finds no significant interaction between childhood trauma and a PRS for MDD in the prediction of MDD (Peyrot et al., 2018). The authors conclude that such inconsistent findings may arise when SNPs that do not moderate the association between childhood maltreatment and risk for MDD are included in a conventional PRS.

Our xPRS approach specifically addresses the issue raised by Peyrot et al. (2018): we focused our xPRS on SNPs that moderate the association between maternal antenatal depressive symptoms and child outcome. The xPRS moderated the relationship between maternal antenatal depressive symptom scores and child internalizing problems to a greater extent than the conventional PRS for ADHD (i.e., $\mathrm{PRS}_{\mathrm{ADHD}}$ ). Specifically, the model using the Best-Fit xPRS explained an additional $9.2 \%$ of the variance in child internalizing symptoms than a model using the Best-Fit $\mathrm{PRS}_{\mathrm{ADHD}}$. We also replicated this finding in an independent cohort. Our xPRS approach adds to a growing number of studies that outline novel approaches to integrate PRS in genome by environment analyses (see Hüls, Ickstadt, Schikowski, \& Krämer, 2017a; Hüls et al., 2017b; Lin, Huang, Liu, Tsai, \& Kuo, 2018).

Our xPRS enrichment analyses reveal candidate gene networks related to neuronal/synaptic function that may moderate the association between maternal antenatal depressive symptoms and child mental health outcomes (see Supplementary Appendix B: Supplementary Data). Qiu et al. (2017) also observe significant enrichment of genes associated with synaptic function within their genetic predictor (a PRS for MDD). Similarly, Poelmans, Pauls, Buitelaar, and Franke (2011) conclude that the top-ranked ADHD-associated genes in previous GWAS literature encode proteins involved in neurite outgrowth, while Hayman and Fernandez (2018) report that ADHD-associated genes contribute to synaptic function. These findings and others (see Franke, Neale, \& Faraone, 2009; Lesch et al., 2008) converge on the role of dendritic spine formation/plasticity in GWASs of child neurodevelopment.

Our conventional PRS (PRS $\mathrm{ADHD}$ ) and the xPRS were informed by a GWAS of child ADHD (Neale et al., 2010). However, both the conventional ADHD PRS and the xPRS moderated the effects of maternal antenatal depressive symptoms on child internalizing rather than externalizing symptoms. This finding could, in part, reflect differences between the cohorts used in the current analysis and the cohorts included in the original GWAS. Importantly, the children included in the original GWAS of ADHD were older (10.5 years) than the children included in the current analysis (5-6 years of age), an age when child psychopathology becomes more clearly differentiated. Our findings may also reflect the heterotypic continuity observed between internalizing symptoms in early childhood and later symptoms of ADHD (Finsaas, Bufferd, Dougherty, Carlson, \& Klein, 2018). Alternatively, it is possible that genetic risk factors for ADHD may not be diagnosis specific. In an analysis of over 13,000 children, Brikell et al. (2020) found that a PRS for
ADHD was more closely associated with a general factor for child psychopathology than for specific symptoms of hyperactivity/impulsivity. These findings suggest that GWAS of ADHD, and genetic predictors based on such GWAS, may be informative for understanding a broader range of child mental health phenotypes. This is a potentially fruitful focus for future analyses with appropriately large data sets and breadth of outcomes. Likewise, it will be interesting to analyze the degree to which an xPRS specific for a certain early life adversity is predictive for other forms of adversity.

Our xPRS analyses provided greater evidence for differential susceptibility than diathesis-stress. Children with higher xPRS showed the highest and the lowest number of internalizing symptoms contingent on level of exposure to maternal depression in pregnancy. Conversely, children with lower xPRS showed similar internalizing symptoms irrespective of the levels of antenatal maternal depression. Our results are consistent with findings of other GxE analyses of emotional/behavioral outcomes, which suggest "vulnerability" genetic risk factors may be better conceptualized as "plasticity" factors (Belsky et al., 2007; Belsky et al., 2009). Our findings suggest that the children most at risk for adverse mental health outcomes may be the same children who would benefit the most from targeted interventions to improve maternal antenatal mental health. Genetically-informed analyses of trials designed to improve antenatal maternal mental health are required to test this hypothesis.

One limitation of our study was the sample size of our cohorts. Nevertheless, the effect size of the interaction between xPRS and antenatal maternal depressive symptoms is moderate (Cohen's $\left.f^{2}=0.21\right)$. This allowed us to detect a significant moderation effect in distinct cohorts from Canada (MAVAN) and the Netherlands (BIBO). We note that both of these cohorts are predominantly Caucasian. Validation of the xPRS approach in more diverse samples is required. Similarly, future studies will determine if the moderating influence of xPRS on the relationship between maternal antenatal depression and child outcome is stable or dynamic across different developmental stages.

Another potential limitation of the current study is our focus on a subset of SNPs identified from a GWAS of child ADHD. It is plausible that there are additional SNPs, not identified from GWAS of ADHD, that moderate the impact of maternal antenatal depression on child outcome and have not been considered in our xPRS. While we acknowledge the potential utility of genome-wide SNP by environment interaction analyses (see Arnau-Soler et al., 2019; Bentley et al., 2019), we were not powered to perform such an analysis. Alternatively, xPRS provides a GWAS-informed approach that is suitable for use in community cohorts, which place a greater emphasis on clinical and environmental phenotyping than sample size. Initiatives such as the Psychiatric Genomics Consortium (Sullivan et al., 2018), PhenX (Hendershot et al., 2015), and the National Institutes of Health-funded Environmental influences on Child Health Outcomes (ECHO) program (Gillman \& Blaisdell, 2018), which harmonize genetic and clinical measures across cohorts, may facilitate future genome-wide SNP by environment interaction analyses.

\section{Conclusion}

There are considerable individual differences in the effects of maternal antenatal depression on child outcome. We describe a novel approach, xPRS, to better describe the genomic basis for 
variation in developmental outcomes associated with early life adversity. Individual differences in susceptibility complicate the development and assessment of interventions targeted solely on the basis of environmental exposures. While PRSs alone are likely to be inadequate, they do provide a pool of genomic variants associated with clinical outcomes of interest and are thus a useful tool for the development of genomic measures. This more targeted GxE approach may better identify children at risk for adverse mental health outcomes following exposure to specific forms of adversity, such as antenatal maternal depression, which in turn may inform targeted prevention/intervention efforts through identification of the most vulnerable children.

Supplementary Material. The supplementary material for this article can be found at https://doi.org/10.1017/S0954579420001418.

Acknowledgments. We acknowledge the families who generously gave their time to participate in the MAVAN and BIBO cohorts. The MAVAN cohort received support from the Canadian Institutes of Health Research and the Ludmer Centre for Neuroinformatics and Mental Health.

We would like to acknowledge the remarkable contribution of Dr. Megan Gunnar to our understanding of child development. Dr. Gunnar's research continues to inspire us to better understand how the early environment shapes child neurodevelopment and challenges us to ask how we can harness this knowledge to improve child outcomes.

Funding Statement. LMC is supported by the Brain Canada Foundation through the Canada Brain Research Fund, with the financial support of Health Canada and Kids Brain Health. MJM is supported by grants from the Hope for Depression Research Foundation, The Canadian Institutes for Health Research, The National Medical Research Council (Singapore), the Natural Sciences \& Engineering Research Council of Canada, The Webster Foundation, The JPB Foundation through a grant to The JPB Research Network on Toxic Stress: A Project of the Center on the Developing Child at Harvard University, and core funding from the Agency for Science, Technology and Research (A`STAR, Singapore). MJM, MSK, and KOD are Fellows of the CIFAR Child and Brain Development Program. KOD is supported by the Canada First Research Excellence Fund Healthy Brains for Healthy Lives initiative at McGill University, the Jacobs Foundation and the Fonds de recherche du Québec-Santé and the Brain and Behavior Research Foundation. CdW is supported by the Netherlands Organization for Scientific Research VIDI grant 575-25-009 and the Jacobs Foundation. RB is supported by a Netherlands Organization for Scientific Research VENI grant (016.195.197), and a Sara van Dam Project Grant of the Royal Netherlands Academy of Arts and Sciences.

Conflicts of Interest. None

\section{References}

Achenbach, T. M. (1991). Integrative Guide to the 1991 CBCL/4-18, YSR, and TRF Profiles. Burlington, VT: University of Vermont, Department of Psychology.

Arnau-Soler, A., Macdonald-Dunlop, E., Adams, M. J., Clarke, T.-K., MacIntyre, D. J., Milburn, K., ... Thomson, P. A. (2019). Genome-wide by environment interaction studies of depressive symptoms and psychosocial stress in UK Biobank and Generation Scotland. Translational Psychiatry, 9, 14. doi:10.1038/s41398-018-0360-y

Babineau, V., Green, C. G., Jolicoeur-Martineau, A., Bouvette-Turcot, A.-A., Minde, K., Sassi, R., ... MAVAN project. (2015). Prenatal depression and 5-HTTLPR interact to predict dysregulation from 3 to 36 months - A differential susceptibility model. Journal of Child Psychology and Psychiatry, 56, 21-29. doi:10.1111/jcpp.12246

Beijers, R., Jansen, J., Riksen-Walraven, M., \& de Weerth, C. (2010). Maternal prenatal anxiety and stress predict infant illnesses and health complaints. Pediatrics, 126, e401-e409. doi:10.1542/peds.2009-3226
Belsky, J. (1997). Variation in susceptibility to environmental influence: An evolutionary argument. Psychological Inquiry, 8, 182-186.

Belsky, J., Bakermans-Kranenburg, M. J., \& van IJzendoorn, M. H. (2007). For better and for worse: Differential susceptibility to environmental influences. Current Directions in Psychological Science, 16, 300-304. doi:10.1111/ j.1467-8721.2007.00525.x

Belsky, J., Jonassaint, C., Pluess, M., Stanton, M., Brummett, B., \& Williams, R. (2009). Vulnerability genes or plasticity genes? Molecular Psychiatry, 14, 746-754. doi:10.1038/mp.2009.44

Belsky, J., Pluess, M., \& Widaman, K. F. (2013). Confirmatory and competitive evaluation of alternative gene-environment interaction hypotheses. Journal of Child Psychology and Psychiatry, 54, 1135-1143. doi:10.1111/jcpp.12075

Bentley, A. R., Sung, Y. J., Brown, M. R., Winkler, T. W., Kraja, A. T., Ntalla, I., ... Cupples, L. A. (2019). Multi-ancestry genome-wide gene-smoking interaction study of 387,272 individuals identifies new loci associated with serum lipids. Nature Genetics, 51, 636-648. doi:10.1038/s41588-019-0378-y

Biederman, J., Newcorn, J. H., \& Sprich, S. (1991). Comorbidity of attention deficit hyperactivity disorder with conduct, depressive, anxiety, and other disorders. American Journal of Psychiatry, 148, 564-577. doi:10.1176/ ajp.148.5.564

Border, R., Johnson, E. C., Evans, L. M., Smolen, A., Berley, N., Sullivan, P. F., \& Keller, M. C. (2019). No support for historical candidate gene or candidate gene-by-interaction hypotheses for major depression across multiple large samples. American Journal of Psychiatry, 176, 376-387. doi:10.1176/ appi.ajp.2018.18070881

Brikell, I., Larsson, H., Lu, Y., Pettersson, E., Chen, Q., Kuja-Halkola, R., ... Martin, J. (2020). The contribution of common genetic risk variants for ADHD to a general factor of childhood psychopathology. Molecular Psychiatry, 25, 1809-1821. doi:10.1038/s41380-018-0109-2.

Brody, G. H., Yu, T., \& Beach, S. R. H. (2015). A differential susceptibility analysis reveals the "who and how" about adolescents' responses to preventive interventions: Tests of first- and second-generation Gene $\mathrm{x}$ Intervention hypotheses. Development and Psychopathology, 27, 37-49. doi:10.1017/ S095457941400128x

Chang, C. C., Chow, C. C., Tellier, L. C. A. M., Vattikuti, S., Purcell, S. M., \& Lee, J. J. (2015). Second-generation PLINK: Rising to the challenge of larger and richer datasets. GigaScience, 4, 1-16. doi:10.1186/ s13742-015-0047-8

Chen, L. M., Yao, N., Garg, E., Zhu, Y., Nguyen, T. T. T., Pokhvisneva, I., ... O'Donnell, K. J. (2018). PRS-on-Spark (PRSoS): A novel, efficient and flexible approach for generating polygenic risk scores. BMC Bioinformatics, 19, 295. doi:10.1186/s12859-018-2289-9

Cicchetti, D., Toth, S. L., \& Handley, E. D. (2015). Genetic moderation of interpersonal psychotherapy efficacy for low-income mothers with major depressive disorder: Implications for differential susceptibility. Development and Psychopathology, 27, 19-35. doi:10.1017/S0954579414001278

Cox, J. L., Holden, J. M., \& Sagovsky, R. (1987). Detection of postnatal depression. Development of the 10-item Edinburgh Postnatal Depression Scale. British Journal of Psychiatry, 150, 782-786.

Cross-Disorder Group of the Psychiatric Genomics Consortium. (2013). Identification of risk loci with shared effects on five major psychiatric disorders: A genome-wide analysis. The Lancet, 381, 1371-1379. doi:10.1016/ S0140-6736(12)62129-1

Demontis, D., Walters, R. K., Martin, J., Mattheisen, M., Als, T. D., Agerbo, E., ... Neale, B. M. (2019). Discovery of the first genome-wide significant risk loci for attention deficit/hyperactivity disorder. Nature Genetics, 51, 63-75. doi:10.1038/s41588-018-0269-7

Duncan, L. E., Pollastri, A. R., \& Smoller, J. W. (2014). Mind the gap: Why many geneticists and psychological scientists have discrepant views about gene-environment interaction $(\mathrm{G} \times \mathrm{E})$ research. American Psychologist, 69, 249-268. doi:10.1037/a0036320

Dunn, E. C., Wiste, A., Radmanesh, F., Almli, L. M., Gogarten, S. M., Sofer, T., ... Smoller, J. W. (2016). Genome-wide association study (GWAS) and genome-wide by environment interaction study (GWEIS) of depressive symptoms in African American and Hispanic/Latina women. Depression and Anxiety, 33, 265-280. doi:10.1002/da.22484

Du Rietz, E., Coleman, J., Glanville, K., Choi, S. W., O’Reilly, P. F., \& Kuntsi, J. (2018). Association of polygenic risk for attention-deficit/hyperactivity 
disorder with co-occurring traits and disorders. Biological Psychiatry: Cognitive Neuroscience and Neuroimaging, 3, 635-643. doi:10.1016/ j.bpsc.2017.11.013

Ellis, B. J., Boyce, W. T., Belsky, J., Bakermans-Kranenburg, M. J., \& van IJzendoorn, M. H. (2011). Differential susceptibility to the environment: A neurodevelopmental theory. Development and Psychopathology, 23, 7-28. doi:10.1017/S0954579410000611

Ficks, C. A., \& Waldman, I. D. (2009). Gene-environment interactions in attention-deficit/hyperactivity disorder. Current Psychiatry Reports, 11, 387-392. doi:10.1007/s11920-009-0058-1

Finsaas, M. C., Bufferd, S. J., Dougherty, L. R., Carlson, G. A., \& Klein, D. N. (2018). Preschool psychiatric disorders: Homotypic and heterotypic continuity through middle childhood and early adolescence. Psychological Medicine, 48, 2159-2168. doi:10.1017/S0033291717003646

Franke, B., Neale, B. M., \& Faraone, S. V. (2009). Genome-wide association studies in ADHD. Human Genetics, 126, 13-50. doi:10.1007/s00439-009-0663-4

Gentile, S. (2017). Untreated depression during pregnancy: Short- and longterm effects in offspring. A systematic review. Neuroscience, 342, 154-166. doi:10.1016/j.neuroscience.2015.09.001

Gillman, M. W., \& Blaisdell, C. J. (2018). Environmental influences on Child Health Outcomes, a research program of the National Institutes of Health. Current Opinion in Pediatrics, 30, 260-262. doi:10.1097/ MOP.0000000000000600

Goodman, S. H., Cullum, K. A., Dimidjian, S., River, L. M., \& Kim, C. Y. (2018). Opening windows of opportunities: Evidence for interventions to prevent or treat depression in pregnant women being associated with changes in offspring's developmental trajectories of psychopathology risk. Development and Psychopathology, 30, 1179-1196. doi:10.1017/ S0954579418000536

Goodman, S. H., Rouse, M. H., Connell, A. M., Broth, M. R., Hall, C. M., \& Heyward, D. (2011). Maternal depression and child psychopathology: A meta-analytic review. Clinical Child and Family Psychology Review, 14, 127. doi:10.1007/s10567-010-0080-1

Graffi, J., Moss, E., Jolicoeur-Martineau, A., Moss, G., Lecompte, V., \& Pascuzzo, K., ... MAVAN Project. (2017). The dopamine D4 receptor gene, birth weight, maternal depression, maternal attention, and the prediction of disorganized attachment at 36 months of age: A prospective gene $\mathrm{x}$ environment analysis. Infant Behavior and Development, 50, 64-77. doi:10.1016/j.infbeh.2017.11.004

Grizenko, N., Fortier, M. E., Zadorozny, C., Thakur, G., Schmitz, N., Duval, R., \& Joober, R. (2012). Maternal stress during pregnancy, ADHD symptomatology in children and genotype: Gene-environment interaction. Journal of the Canadian Academy of Child and Adolescent Psychiatry, 21, 9-15.

Groen-Blokhuis, M. M., Middeldorp, C. M., Kan, K.-J., Abdellaoui, A., van Beijsterveldt, C. E. M., Ehli, E. A., ... Boomsma, D. I. (2014). Attention-deficit/hyperactivity disorder polygenic risk scores predict attention problems in a population-based sample of children. Journal of the American Academy of Child and Adolescent Psychiatry, 53, 1123-1129. doi:10.1016/j.jaac.2014.06.014

Hayman, V., \& Fernandez, T. V. (2018). Genetic insights into ADHD biology. Frontiers in Psychiatry, 9, 251. doi:10.3389/fpsyt.2018.00251

Hendershot, T., Pan, H., Haines, J., Harlan, W. R., Marazita, M. L., McCarty, C. A., ... Hamilton, C. M. (2015). Using the PhenX Toolkit to add standard measures to a study. Current Protocols in Human Genetics, 86, 1.21.2121.21.17. doi:10.1002/0471142905.hg0121s86

Hüls, A., Ickstadt, K., Schikowski, T., \& Krämer, U. (2017a). Detection of gene-environment interactions in the presence of linkage disequilibrium and noise by using genetic risk scores with internal weights from elastic net regression. BMC Genetics, 18, 55. doi:10.1186/s12863-017-0519-1

Hüls, A., Krämer, U., Carlsten, C., Schikowski, T., Ickstadt, K., \& Schwender, H. (2017b). Comparison of weighting approaches for genetic risk scores in gene-environment interaction studies. BMC Genetics, 18, 115. doi:10.1186/ s12863-017-0586-3

Keller, M. C. (2014). Gene x environment interaction studies have not properly controlled for potential confounders: The problem and the (simple) solution. Biological Psychiatry, 75, 18-24. doi:10.1016/j.biopsych.2013.09.006

Kuhn, M. (2008). Building predictive models in $\mathrm{R}$ using the caret package. Journal of Statistical Software, 28, 1-26. doi:10.18637/jss.v028.i05.
Lesch, K.-P., Timmesfeld, N., Renner, T. J., Halperin, R., Roser, C., Nguyen, T. T., ... Jacob, C. (2008). Molecular genetics of adult ADHD: Converging evidence from genome-wide association and extended pedigree linkage studies. Journal of Neural Transmission, 115, 1573-1585. doi:10.1007/s00702-008-0119-3

Lin, W.-Y., Huang, C.-C., Liu, Y.-L., Tsai, S.-J., \& Kuo, P.-H. (2018). Polygenic approaches to detect gene-environment interactions when external information is unavailable. Briefings in Bioinformatics, 20, 2236-2252. doi:10.1093/bib/bby086.

Manuck, S. B., \& McCaffery, J. M. (2014). Gene-environment interaction. Annual Review of Psychology, 65, 41-70. doi:10.1146/annurev-psych-010213-115100

Martin, J., Hamshere, M. L., Stergiakouli, E., O’Donovan, M. C., \& Thapar, A. (2014). Genetic risk for attention-deficit/hyperactivity disorder contributes to neurodevelopmental traits in the general population. Biological Psychiatry, 76, 664-671. doi:10.1016/j.biopsych.2014.02.013

Martin, J., Walters, R. K., Demontis, D., Mattheisen, M., Lee, S. H., Robinson, E., ... Neale, B. M. (2018). A genetic investigation of sex bias in the prevalence of attention-deficit/hyperactivity disorder. Biological Psychiatry, 83, 1044-1053. doi:10.1016/j.biopsych.2017.11.026

McCarthy, S., Das, S., Kretzschmar, W., Delaneau, O., Wood, A. R., Teumer, A., ... Haplotype Reference Consortium. (2016). A reference panel of 64,976 haplotypes for genotype imputation. Nature Genetics, 48, 12791283. doi:10.1038/ng.3643

Meaney, M. J. (2018). Perinatal maternal depressive symptoms as an issue for population health. American Journal of Psychiatry, 175, 1084-1093. doi:10.1176/appi.ajp.2018.17091031

Mullins, N., Power, R. A., Fisher, H. L., Hanscombe, K. B., Euesden, J., Iniesta, R., ... Lewis, C. M. (2016). Polygenic interactions with environmental adversity in the aetiology of major depressive disorder. Psychological Medicine, 46, 759-770. doi:10.1017/S0033291715002172

Neale, B. M., Medland, S. E., Ripke, S., Asherson, P., Franke, B., Lesch, K.-P., ... Nelson, S. (2010). Meta-analysis of genome-wide association studies of attention deficit/hyperactivity disorder. Journal of the American Academy of Child and Adolescent Psychiatry, 49, 884-897. doi:10.1016/j.jaac.2010.06.008

O’Donnell, K. A., Gaudreau, H., Colalillo, S., Steiner, M., Atkinson, L., Moss, E., ... MAVAN Research Team. (2014). The Maternal Adversity, Vulnerability and Neurodevelopment project: Theory and methodology. Canadian Journal of Psychiatry, 59, 497-508. doi:10.1177/070674371405900906

O’Donnell, K. J., Glover, V., Barker, E. D., \& O’Connor, T. G. (2014). The persisting effect of maternal mood in pregnancy on childhood psychopathology. Development and Psychopathology, 26, 393-403. doi:10.1017/ S0954579414000029

O’Donnell, K. J., Glover, V., Holbrook, J. D., \& O'Connor, T. G. (2014) Maternal prenatal anxiety and child brain-derived neurotrophic factor (BDNF) genotype: Effects on internalizing symptoms from 4 to 15 years of age. Development and Psychopathology, 26, 1255-1266. doi:10.1017/ S095457941400100X

O’Donnell, K. J., Glover, V., Lahti, J., Lahti, M., Edgar, R. D., Räikkönen, K., \& O'Connor, T. G. (2017). Maternal prenatal anxiety and child COMT genotype predict working memory and symptoms of ADHD. PLoS One, 12, 1-16. doi:10.1371/journal.pone.0177506

O'Donnell, K. J., \& Meaney, M. J. (2017). Fetal origins of mental health: The Developmental Origins of Health and Disease hypothesis. American Journal of Psychiatry, 174, 319-328. doi:10.1176/appi.ajp.2016.16020138

Patterson, N., Price, A. L., \& Reich, D. (2006). Population structure and eigenanalysis. PLoS Genetics, 2, 2074-2093. doi:10.1371/journal.pgen. 0020190

Pearson, R. M., Bornstein, M. H., Cordero, M., Scerif, G., Mahedy, L., Evans, J., ... Stein, A. (2016). Maternal perinatal mental health and offspring academic achievement at age 16: The mediating role of childhood executive function. Journal of Child Psychology and Psychiatry, 57, 491-501. doi:10.1111/jcpp.12483

Pearson, R. M., Evans, J., Kounali, D., Lewis, G., Heron, J., Ramchandani, P. G., ... Stein, A. (2013). Maternal depression during pregnancy and the postnatal period: Risks and possible mechanisms for offspring depression at age 18 years. JAMA Psychiatry, 70, 1312-1319. doi:10.1001/ jamapsychiatry.2013.2163

Peyrot, W. J., Milaneschi, Y., Abdellaoui, A., Sullivan, P. F., Hottenga, J. J., Boomsma, D. I., \& Penninx, B. W. J. H. (2014). Effect of polygenic risk 
scores on depression in childhood trauma. British Journal of Psychiatry, 205, 113-119. doi:10.1192/bjp.bp.113.143081

Peyrot, W. J., Van der Auwera, S., Milaneschi, Y., Dolan, C. V., Madden, P. A. F., Sullivan, P. F., ... Penninx, B. W. J. H. (2018). Does childhood trauma moderate polygenic risk for depression? A meta-analysis of 5765 subjects from the Psychiatric Genomics Consortium. Biological Psychiatry, 84, 138-147. doi:10.1016/j.biopsych.2017.09.009

Plomin, R., \& Simpson, M. A. (2013). The future of genomics for developmentalists. Development and Psychopathology, 25, 1263-1278. doi:10.1017/ S0954579413000606

Pluess, M., \& Belsky, J. (2009). Differential susceptibility to rearing experience: The case of childcare. Journal of Child Psychology and Psychiatry and Allied Disciplines, 50, 396-404. doi:10.1111/j.1469-7610.2008.01992.x

Poelmans, G., Pauls, D. L., Buitelaar, J. K., \& Franke, B. (2011). Integrated genome-wide association study findings: Identification of a neurodevelopmental network for attention deficit hyperactivity disorder. American Journal of Psychiatry, 168, 365-377. doi:10.1176/appi.ajp.2010.10070948

Pop, V. J., Komproe, I. H., \& van Son, M. J. (1992). Characteristics of the Edinburgh post natal depression scale in the Netherlands. Journal of Affective Disorders, 26, 105-110.

Price, A. L., Patterson, N. J., Plenge, R. M., Weinblatt, M. E., Shadick, N. A., \& Reich, D. (2006). Principal components analysis corrects for stratification in genomewide association studies. Nature Genetics, 38, 904-909. doi:10.1038/ng1847

Qiu, A., Shen, M., Buss, C., Chong, Y. S., Kwek, K., Saw, S. M., ... Meaney, M. J. (2017). Effects of antenatal maternal depressive symptoms and socioeconomic status on neonatal brain development are modulated by genetic risk. Cerebral Cortex, 27, 3080-3092. doi:10.1093/cercor/bhx065

Radloff, L. S. (1977). The CES-D scale: A self-reported depression scale for research in the general population. Applied Psychological Measurement, 1, 385-401. doi:10.1177/014662167700100306

Rietveld, C. A., Medland, S. E., Derringer, J., Yang, J., Esko, T., Martin, N. W., ... Koellinger, P. D. (2013). GWAS of 126,559 individuals identifies genetic variants associated with educational attainment. Science, 340, 1467-1471. doi:10.1126/science. 1235488

Roisman, G. I., Newman, D. A., Fraley, R. C., Haltigan, J. D., Groh, A. M., \& Haydon, K. C. (2012). Distinguishing differential susceptibility from diathesisstress: Recommendations for evaluating interaction effects. Development and Psychopathology, 24, 389-409. doi:10.1017/S0954579412000065

Rutter, M. (2007). Gene-environment interdependence. Developmental Science, 10, 12-18. doi:10.1111/j.1467-7687.2007.00557.x

Sfelinioti, S., \& Livaditis, M. (2017). Association of maternal depression with children's attention deficit hyperactivity disorder. Psychiatriki, 28, 251258. doi:10.22365/jpsych.2017.283.251

Shevlin, M., McElroy, E., \& Murphy, J. (2017). Homotypic and heterotypic psychopathological continuity: A child cohort study. Social Psychiatry and Psychiatric Epidemiology, 52, 1135-1145. doi:10.1007/s00127-017-1396-7

Silveira, P. P., Pokhvisneva, I., Gaudreau, H., Atkinson, L., Fleming, A. S., Sokolowski, M. B., ... MAVAN research team. (2018). Fetal growth interacts with multilocus genetic score reflecting dopamine signaling capacity to predict spontaneous sugar intake in children. Appetite, 120, 596-601. doi:10.1016/j.appet.2017.10.021

Silveira, P. P., Pokhvisneva, I., Parent, C., Cai, S., Rema, A. S. S., Broekman, B. F. P., ... Meaney, M. J. (2017). Cumulative prenatal exposure to adversity reveals associations with a broad range of neurodevelopmental outcomes that are moderated by a novel, biologically informed polygenetic score based on the serotonin transporter solute carrier family C6, member 4 (SLC6A4) gene expression. Development and Psychopathology, 29, 16011617. doi:10.1017/S0954579417001262

Stergiakouli, E., Martin, J., Hamshere, M. L., Heron, J., St Pourcain, B., Timpson, N. J., ... Davey Smith, G. (2017). Association between polygenic risk scores for attention-deficit hyperactivity disorder and educational and cognitive outcomes in the general population. International Journal of Epidemiology, 46, 421-428. doi:10.1093/ije/ dyw216

Stergiakouli, E., Martin, J., Hamshere, M. L., Langley, K., Evans, D. M., St Pourcain, B., ... Davey Smith, G. (2015). Shared genetic influences between attention-deficit/hyperactivity disorder (ADHD) traits in children and clinical ADHD. Journal of the American Academy of Child and Adolescent Psychiatry, 54, 322-327. doi:10.1016/j.jaac.2015.01. 010

Sullivan, P. F., Agrawal, A., Bulik, C. M., Andreassen, O. A., Børglum, A. D., Breen, G., ... O'Donovan, M. C. (2018). Psychiatric genomics: An update and an agenda. American Journal of Psychiatry, 175, 15-27. doi:10.1176/ appi.ajp.2017.17030283

Sullivan, P. F., Daly, M. J., \& O’Donovan, M. (2012). Genetic architectures of psychiatric disorders: The emerging picture and its implications. Nature Reviews Genetics, 13, 537-551. doi:10.1038/nrg3240

Thompson, P. M., Stein, J. L., Medland, S. E., Hibar, D. P., Vasquez, A. A., Renteria, M. E., ... Alzheimer's Disease Neuroimaging Initiative, E. C. I. C. S. Y. S. G. (2014). The ENIGMA Consortium: Large-scale collaborative analyses of neuroimaging and genetic data. Brain Imaging and Behavior, 8, 153-182. doi:10.1007/s11682-013-9269-5

Van der Auwera, S., Peyrot, W. J., Milaneschi, Y., Hertel, J., Baune, B., Breen, G., ... Grabe, H. (2018). Genome-wide gene-environment interaction in depression: A systematic evaluation of candidate genes. American Journal of Medical Genetics Part B: Neuropsychiatric Genetics, 177B, 40-49. doi:10.1002/ajmg.b.32593

van der Toorn, S. L. M., Huizink, A. C., Utens, E. M. J. W., Verhulst, F. C., Ormel, J., \& Ferdinand, R. F. (2010). Maternal depressive symptoms, and not anxiety symptoms, are associated with positive mother-child reporting discrepancies of internalizing problems in children: A report on the TRAILS Study. European Child and Adolescent Psychiatry, 19, 379-388. doi:10.1007/s00787-009-0062-3

van Ijzendoorn, M. H., \& Bakermans-Kranenburg, M. J. (2015). Genetic differential susceptibility on trial: Meta-analytic support from randomized controlled experiments. Development and Psychopathology, 27, 151-62. doi: $10.1017 /$ S0954579414001369

Verhulst, F. C., Akkerhuis, G. W., \& Althaus, M. (1985). Mental health in Dutch children: (I). A cross-cultural comparison. Acta Psychiatrica Scandinavica. Supplementum, 72, 1-108. doi:10.1111/j.1600-0447.1985.tb10512.x

Visscher, P. M., Hill, W. G., \& Wray, N. R. (2008). Heritability in the genomics era-concepts and misconceptions. Nature Reviews Genetics, 9, 255-266. doi:10.1038/nrg2322

Wray, N. R., Goddard, M. E., \& Visscher, P. M. (2007). Prediction of individual genetic risk to disease from genome-wide association studies. Genome Research, 17, 1520-1528. doi:10.1101/gr.6665407.1

Wray, N. R., Lee, S. H., Mehta, D., Vinkhuyzen, A. A. E., Dudbridge, F., \& Middeldorp, C. M. (2014). Research review: Polygenic methods and their application to psychiatric traits. Journal of Child Psychology and Psychiatry, 55, 1068-1087. doi:10.1111/jcpp.12295 